the hot sun, he felt warm indeed. Being cold blooded does have its disadvantages if you are a snake. Have you ever considered how inconvenient it would be if you could only digest your food when the temperature of your surroundings was within a certain limited range? Some snakes are affected that way. We could understand Cedric's not eating cold beef when he was accustomed to eating only live food. but we wondered at his vomiting it back up once it was in his stomach. Warming Cedric up to a cozy 80 degrees before feeding him solved the problem. Then the digestive juices were able to accomplish their task, and a two month's fast was broken. A fast cif that length is no record for a snake; some snakes do not eat for a year after they are born.

Our native Saskatchewan snakes, including the Smooth Green Snake, Garter Snake, Red-bellied Snake, Bull Snake and Hognosed Snake, are for the most part easily tamed and make excellent pets. The only poisonous snake found in Saskatchewan, the Prairie Rattler, is confined to the southern areas and is readily distinguishable by the rattles on its tail. The Bull Snake will, by vigorously vibrating its tail in dried weeds, make a convincing enough rattle to frighten away the uninitiated. Cedric, who ordinarily is most docile and never emits a hiss from one month to the next, reacted violently recently when he saw a dog. It was hard to believe that such a docile snake could put on such a ferocious appearance. It took him fifteen minutes to subside and resume a more harmless demeanour. It certainly was an impressive sight, even though I suspected that Cedric didn't mean a hiss of it but sincerely hoped the dog would take the warning to heart.

At present, Cedric, a live Bull Snake, is on display at the museum. Since life is an indeterminate factor with snakes, as with the human species, we cannot guarantee that Cedric will always be on display alive. However, all the snakes mentioned in this article are on display in a stuffed condition. I might add that Cedric has the habit of remain. ing so motionless that he too is frequently mistaken for the stuffed article. Such indignities Cedric takes unblinkingly. You would, too, if you had no eyelids.

Note: Cedric, the Bull Snake, has played an important role in the museum's educational program; some 6,000 school children having handled this snake in the past 12 months. All school groups touring the museum now enjoy the benefits of numerous tactile-aids, an activity aimed at achieving a more intimate contact between the audience and the subject.

\title{
Meteors and Meteorites
}

\section{By JOHN HODGES, Regina Astronomical Society}

The opportunities that remain for amateur research in astronomy are getting fewer in number each year. There are very few subjects that the amateur can investigate with the krowledge that he can be of help to the professional. Any society has thereiore to select from a very narrow range of endeavours. The Regina "star gazers" have selected meteors and meteorites as their particular study because they know that the professional is always glad to hear about observations of these visitors from space. We can say that in this field the more observers the better. At any one location, an observer sees only one one hundred thousandth of the visible sky. This leaves considerable room for more amateurs, a very happy situation.

For six years, the Regina group has watched the meteors that appear to radiate from the constellation of Perseus about the middle of August. So far we have logged about two thousand of these meteors, recording identity, brilliance, characteristics of flight, and colour. As we gained experience in this field, we were able to get some good photographs. The first Spectrogram taken by amateurs in Canada was obtained in August, 1955. A spectrogram is a picture which enables the material in a meteor to be identified, after the 
meteor itself has disintegrated high in the atmosphere due to its speed and the friction with the air.

Members of the Regina Astronomical Society were invited to be present at the annual picnic held by the Regina Natural History Society in Hidden Valley on September 16th of this year and to show nature lovers the heavens after the evening wiener roast. A telescope had been transported (lugged would be a more appropriate word) to the crest of a nearby hill, and the clear blue sky promised excellent "seeing" conditions. Suddenly what seemed to be a jet trail caught the group's attention. Nature, as usual without warning, had put on a display that is seldom seen. A daylight fireball had come into our atmosphere, which made a good show because of its size . . . if you knew what really had happened. Fortunately, the amateur astronomers did know and immediately told everyone present. Some doubted their statements, and the sun had actually set before they realized that a large meteor had fallen, not a jet.

Many have inquired about these rare and unusual pieces of material. Have they been known to do damage? Yes, many times. Twenty-two occasions are known when meteorites have struck buildings. Some near misses have occurred with people as targets, but as yet no official report exists of the loss of human life. However, a large herd of reindeer was completely annihilated on the June 30, 1908 fall in Siberia.

Up until 1953 only 24 meteorites had been recovered in Canada. Many of these are to be seen only in museums across the border. The difficulty lies in recognizing a meteorite should you stumble on one. A few simple rules will help. Meteorites are usually a chocolate colour and somewhat smooth, as if polished. However, the surface will have "thumb prints", making it uneven. If the meteorite has lain on or in the ground for some time, this coating will have disappeared. A close look at the texture of the stone will cften reveal a mineral content of iron, and the stone itself is heavier than the more familiar rocks.

What are meteorites made of, and have new elements been found in them? This is a frequent question. Those that have more metals than stone in them are called Irons (Siderites) and those containing more rock material are called Stones (Aerolites). The rock type often found in meteorites is olivine and pyroxene, always with traces of metal. Most of the elements have been found in meteors but no unknown or new element has been discovered or is expected. New compounds, particularly of metals, are frequently found.

Scientists have only 1400 specimens to work with. As these fragments are the only material we have from the area outside our atmosphere, they form a very valuable small sampling of matter as it exists away from our earth.

As meteors enter our gaseous envelope they are travelling at high speeds. The deeper the atmosphere penetrated, the denser it becomes, and the greater the resulting friction. Most of the "shooting stars" seen as short bright streaks in the night sky are particles the size of a grain of wheat. They are approximately 60 or 70 miles above the earth's surface. The atmosphere at this altitude is very thin indeed. but there is nevertheless sufficient present for the meteor to be consumed as a result of the friction occasioned by its passage through this air.

How many meteors are of sufficient size to land on the earth's surface? Some scientists estimate that only about three meteorites reach the earth's surface each day. You can see, therefore, that a meteorite in Saskatchewan is a rare phenomenon. No wonder excitment ran high on Sept. 16 among the amateur astronomers at Hidden Valley. Should this meteorite be recovered by the Regina group you will read much more about this spectacular fireball and we shall know a little more about matter from outer space.

CORRECTION: Doug Gilroy's photo of a Sharp-tailed Grouse on page 86 of the last BLUE JAY was incorrectly credited to F. W. Lahrman. We regret this error. 